\title{
Change in serum 25-hydroxyvitamin D and parallel change in depressive symptoms in Dutch older adults
}

\author{
Liset E M Elstgeest ${ }^{1}$, Elisa J de Koning², Ingeborg A Brouwer ${ }^{1}$, Natasja M van Schoor ${ }^{2}$, Brenda W J H Penninx ${ }^{3}$ \\ and Marjolein Visser ${ }^{1}$
}

1Department of Health Sciences, Faculty of Science, Vrije Universiteit Amsterdam, Amsterdam Public Health research institute, Amsterdam, the Netherlands, ${ }^{2}$ Department of Epidemiology and Biostatistics, Amsterdam Public Health research institute, VU University Medical Center, Amsterdam, the Netherlands, and ${ }^{3}$ Department of Psychiatry, Amsterdam Public Health research institute, VU University Medical Center/GGZ inGeest, Amsterdam,

the Netherlands

Correspondence should be addressed to L E M Elstgeest

Email

liset.elstgeest@vu.nl

\begin{abstract}
Objective: Previous prospective studies on the association between vitamin D status and depression used a single 25-hydroxyvitamin D (25(OH)D) measurement. We investigated the association between change in serum 25(OH)D and parallel change in depressive symptoms over time in Dutch older adults.

Design: A population-based, prospective study in two cohorts of older men and women from the Longitudinal Aging Study Amsterdam.

Methods: Serum 25(OH)D concentrations were determined at two time points: in 1995/1996 and 13 years later in the older cohort (aged 65-88y, $n=173$ ) and in 2002/2003 and 6 years later in the younger cohort (55-65 years, $n=450)$. At these time points, depressive symptoms were measured with the Center for Epidemiologic Studies Depression scale (CES-D). Associations were tested by multiple linear regression analyses.

Results: During follow-up, serum 25(OH)D concentrations increased in $32.4 \%$ of the older cohort and in $69.8 \%$ of the younger cohort. In the older cohort, change in 25(OH)D was not associated with change in CES-D score. In the younger cohort, no associations were observed in participants with higher baseline 25(OH)D concentrations (>58.6 nmol/L), but in those with lower baseline 25(OH)D concentrations, an increase in 25(OH)D was associated with a decrease in CES-D score (adjusted B per $10 \mathrm{nmol} / \mathrm{L} 25(\mathrm{OH}) \mathrm{D}$ increase: $-0.62(95 \% \mathrm{Cl}:-1.17,-0.07))$.

Conclusions: Our study suggests that over 6 years, an increase in serum 25(OH)D is associated with a small decrease in depressive symptoms in young older adults with lower baseline 25(OH)D. Well-designed intervention trials are required to determine causality.
\end{abstract}

\section{Introduction}

Depression is a major cause of disability and common in older adults $(1,2)$. Clinically relevant depressive symptoms affect 8 to $16 \%$ of the community-dwelling older population, and prevalence estimates of major depression in this population range from 1 to $4 \%$ (3). Depression has adverse health consequences, such as disability, cardiovascular disease, diabetes and premature death, as well as social and economic consequences (4). However, the aetiology of late-life depression is poorly understood.

Several pathways are involved in the aetiology of latelife depression. Vitamin D, a neurosteroid hormone, may 
play a role in the development of depression, as vitamin D receptors and the activating enzyme $1-\alpha$-hydroxylase are present in areas of the human brain that are related to mood $(5,6)$. In addition, the active metabolite of vitamin D, 1,25-dihydroxyvitamin $\mathrm{D}$, influences the synthesis of monoamine neurotransmitters such as serotonin. This metabolite also affects the regulation of neurotrophic factors and stimulates anti-inflammatory actions in the brain $(6,7,8)$. Low serum 25-hydroxyvitamin D $(25(\mathrm{OH}) \mathrm{D})$ concentrations are highly prevalent in older adults, as a result of reduced exposure to sunlight, a decreased efficiency of the skin to synthesise vitamin $D_{3}$ and lower dietary intake (9).

Previous research has suggested an association between vitamin $\mathrm{D}$ status and depression. In many crosssectional studies, lower 25(OH)D concentrations were associated with a higher risk of depressive symptoms or depression (e.g. $(10,11)$ ), while in others, vitamin D and depression were not associated $(12,13)$. Prospective studies showed a higher incidence of depressive symptoms or depression over 1-6 years in older persons who had low baseline vitamin D levels $(14,15,16,17$, 18). However, no prospective associations were found over 4-15 years in older adults $(19,20)$, older men $(21,22)$ and adults $(23)$. Similarly, we recently found no cross-sectional and prospective associations of serum $25(\mathrm{OH}) \mathrm{D}$ concentrations with depressive symptoms in Dutch older men and women, except for a higher risk of depressive symptoms over 6 years in older women with baseline 25(OH)D concentrations below $75 \mathrm{nmol} / \mathrm{L}(24)$. Differences in measures of vitamin D status and depression, study populations, analysis techniques, covariates and latitude may have given rise to these inconsistencies. Furthermore, experimental studies have found inconsistent results as well (e.g. $(25,26))$. Meta-analyses of randomised controlled trials (RCTs) did not find support for the efficacy of vitamin D supplementation in depression; however, heterogeneity between the included trials was high $(27,28,29,30)$. A recent review on observational studies and RCTs has indicated that vitamin D deficiency may be a risk factor for late-life depression based on observational data but not on experimental data (31).

Previous research thus shows that the potential causal role of vitamin D status in depression risk is currently not clear. Next to well-designed RCTs, prospective studies are of interest to gain a better insight into this association in the general population. One of the limitations of all previous prospective studies is that only a single measurement of serum 25(OH)D was used $(14,15,16,17,18,19,20,21,22,23,24)$. Vitamin
D levels vary due to changes in sunlight exposure, diet and supplement use $(32,33)$; therefore, multiple intra-individual measurements are needed for a better understanding of the longitudinal association. To date, no prospective study has addressed the association between changes in serum $25(\mathrm{OH}) \mathrm{D}$ concentrations and changes in depressive symptoms over time. Within two cohorts of the Longitudinal Aging Study Amsterdam (LASA), repeated measurements of serum $25(\mathrm{OH}) \mathrm{D}$ and depressive symptoms provided the opportunity to prospectively study whether changes in serum 25(OH)D over time are associated with parallel changes in depressive symptoms in Dutch older adults. We hypothesised that an increase in $25(\mathrm{OH}) \mathrm{D}$ concentration would lead to a decrease in severity of depressive symptoms.

\section{Subjects and methods}

\section{Study population}

LASA is an ongoing Dutch cohort study on the determinants, trajectories and consequences of physical, cognitive, emotional and social functioning in relation to ageing. Participants were recruited from three geographic regions in the Netherlands, constituting a nationally representative sample of the Dutch older population. Measurement cycles are carried out every 3 years at the participants' homes, including a main interview, medical interview and questionnaire. The Medical Ethics Committee of the VU University Medical Center (VUmc) approved the study, and all participants gave informed consent. A detailed description of the sampling and data collection procedures can be found elsewhere $(34,35)$.

\section{Participants}

For the present study, data from two LASA cohorts were used. At LASA's start in 1992/1993, 3107 subjects aged 55-85 years were enrolled in the first cohort ('older cohort'). At the second measurement cycle (1995/1996, 'baseline' of this cohort), persons aged $\geq 65$ years who participated in the medical interview $(n=1509)$ were asked to donate a blood sample. Serum 25(OH)D concentration was measured in 1320 persons. Serum $25(\mathrm{OH}) \mathrm{D}$ was again measured 13 years later $(2008 / 2009$, $n=390)$. For this study, persons with $25(\mathrm{OH}) \mathrm{D}$ measurements at both cycles were selected $(n=175)$. Two persons were excluded because of missing data on 
baseline covariates, resulting in an analytical sample of 173 persons. The recruitment and exclusion of persons from the older cohort are shown in Fig. 1A; attrition was mainly due to mortality (63.0\%) (34).

In 2002/2003, a second LASA cohort was recruited consisting of 1002 persons aged 55-65 years ('younger cohort'). The medical interview was completed by 919 persons. Serum 25(OH)D concentration was measured in 2002/2003 (baseline, $n=739$ ) and 6 years later $(2008 / 2009, n=525)$. A total of 458 persons had $25(\mathrm{OH}) \mathrm{D}$ measurements at both cycles, of which eight were excluded due to missing data on the Center for Epidemiologic Studies Depression scale (CES-D) at follow-up $(n=1)$ or on baseline covariates $(n=7)$. The recruitment and exclusion of persons from the younger cohort are shown in Fig. 1B.

\section{Depression measurements}

At all measurement cycles, depressive symptoms were assessed by the CES-D, a 20-item self-report scale about depressive symptoms experienced in the previous week (36). The CES-D has been widely used in older populationbased samples and is a valid and reliable instrument for Dutch older adults (37). Total scores range from 0 to 60, with a higher score indicating more depressive symptoms. Change in depressive symptoms over 13 or 6 years was calculated by subtracting the CES-D score at baseline from the score at the follow-up cycle.

\section{5(OH)D measurements}

Morning blood samples were drawn in 1995/1996 (older cohort) and 2002/2003 (younger cohort). Participants
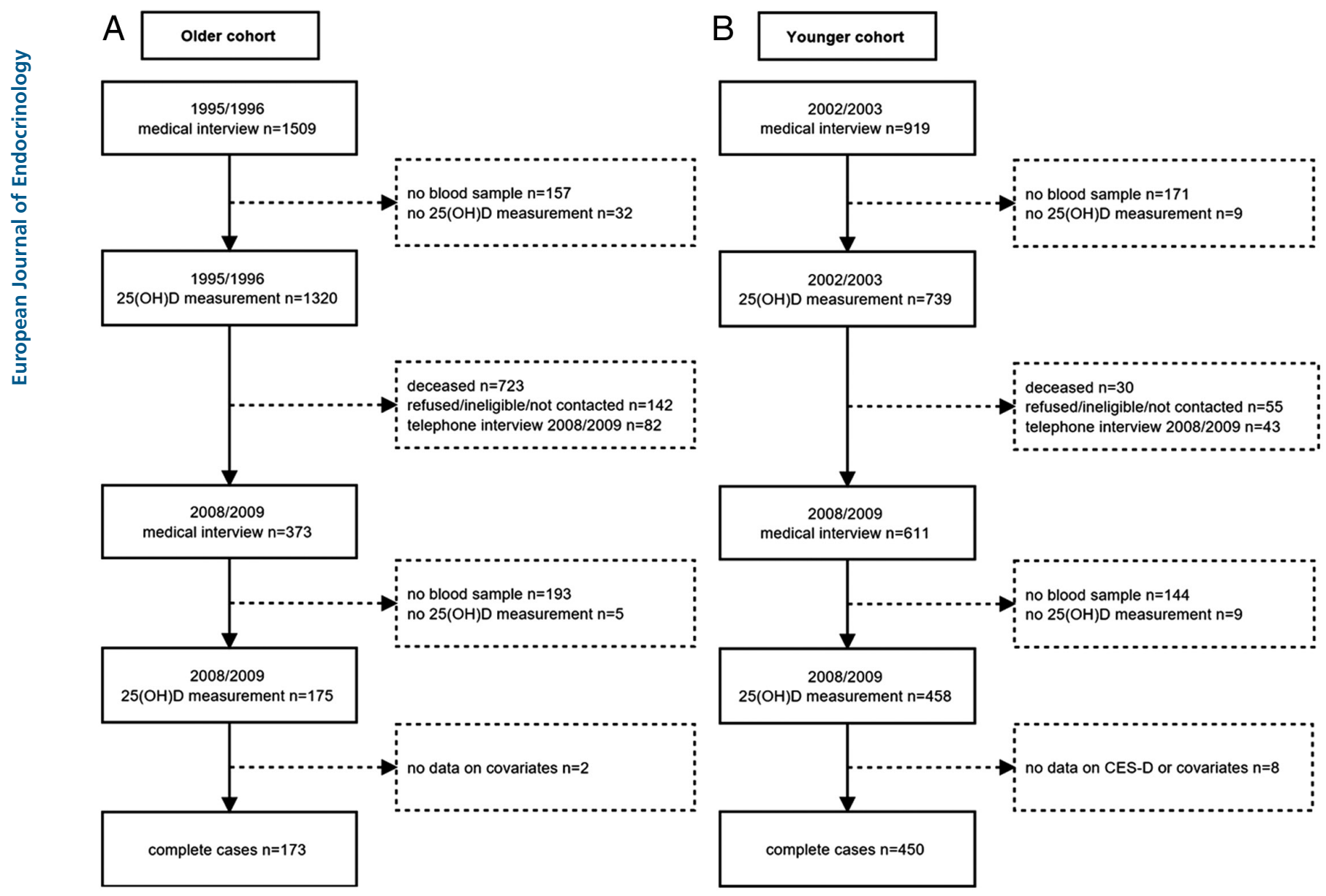

\section{Figure 1}

Flowcharts of the older cohort (A) and the younger cohort (B). 25(OH)D, 25-hydroxyvitamin D; CES-D, Center for Epidemiologic Studies Depression scale. 
were allowed to have tea and toast for breakfast, but no dairy products. In 2009 (both cohorts), fasting blood samples were drawn: participants were not allowed to take any food or drink from midnight. All samples were centrifuged and stored at $-20^{\circ} \mathrm{C}$ until $25(\mathrm{OH}) \mathrm{D}$ determination in 1997/1998 (1995/1996 samples) and in 2010/2011 (2002/2003 and 2009 samples). A competitive protein-binding assay was used in 1997/1998 (Nichols Diagnostics Capistrano, CA, USA; interassay coefficient of variation $(\mathrm{CV})$ : $10 \%)$, whereas a radioimmunoassay was used in 2010/2011 (Diasorin, Stillwater, Minnesota, USA; interassay CV: 10\%). All measurements were carried out at the Endocrine Laboratory of the VUmc.

Before change in $25(\mathrm{OH}) \mathrm{D}$ concentration could be calculated, the $25(\mathrm{OH}) \mathrm{D}$ measurements needed to be (1) standardised for assay and (2) corrected for season. First, as part of the 7th Framework Programme project ODIN, all serum $25(\mathrm{OH}) \mathrm{D}$ data have been standardised by applying the Vitamin D Standardisation Program protocols $(38,39)$. Without differences in assay, $25(\mathrm{OH}) \mathrm{D}$ change can be properly calculated (30). Second, individual concentrations were deseasonalised before calculating the intra-individual change, as blood samples were drawn throughout the year and $25(\mathrm{OH}) \mathrm{D}$ concentrations vary across seasons (highest in summer and autumn, lowest in winter and spring) due to changes in ultraviolet radiation exposure $(32,40)$. For this, a sinusoidal regression model was fitted:

Original 25 $(\mathrm{OH}) \mathrm{D}$ concentration $=\beta_{0}+\beta_{1} \sin (2 \pi T / 365.25)$

$$
+\beta_{2} \cos (2 \pi T / 365.25)
$$

where original $25(\mathrm{OH}) \mathrm{D}$ concentration denotes the standardised $25(\mathrm{OH}) \mathrm{D}$ concentration, $T$ denotes the day of the year of blood draw and $\beta_{j}(j=0,1,2)$ are estimated regression coefficients. To obtain individual deseasonalised 25(OH)D concentrations, the residuals (difference between the predicted value and the original value) from this model were added to the annual mean of the model (the intercept: $\left.\beta_{0}\right)(41,42)$. In this way, the seasonal variation of $25(\mathrm{OH}) \mathrm{D}$ concentration was adjusted for. Deseasonalising was performed separately for each cohort and each measurement cycle: for 1995/1996 and 2009 for the older cohort and for 2002/2003 and 2009 for the younger cohort. Subsequently, intra-individual change in $25(\mathrm{OH}) \mathrm{D}$ concentration was calculated by subtracting the standardised, deseasonalised 25(OH)D concentration at baseline from the standardised, deseasonalised 25(OH)D concentration at follow-up (13 or 6 years later).
Unless otherwise specified, standardised, deseasonalised $25(\mathrm{OH}) \mathrm{D}$ data were used and reported in this study.

\section{Other variables}

Potential confounders were examined at baseline and included sex, age, education level, BMI, smoking status, alcohol use, physical activity and number of chronic diseases. Data on sex and age were derived from municipal registries. Participants were asked about their highest completed level of education, and this was converted into education years. BMI was calculated as measured body weight (in $\mathrm{kg}$ ) divided by squared measured body height (in $\mathrm{m}$ ). Self-reported smoking status was categorised into never, former and current smoking. Categories of selfreported alcohol use were no, light, moderate and (very) excessive (43). Physical activity during the past 2 weeks (walking outdoors, cycling, sports and heavy household activities, in min/day) was assessed using the validated LASA Physical Activity Questionnaire (44). Self-reported number of chronic diseases included seven major somatic diseases: asthma/chronic obstructive pulmonary disease, cardiac disease, peripheral arterial disease, diabetes mellitus, cerebrovascular accident/stroke, osteoarthritis/ rheumatoid arthritis and cancer. Use of antidepressants (yes/no, only used in sensitivity analyses) was retrieved during the medical interview using ATC codes of the medications that were used at that time by the participant.

\section{Statistical analyses}

As age range and follow-up time between the two cycles differed between the two cohorts, all analyses were conducted separately for each cohort. Absolute change in $25(\mathrm{OH}) \mathrm{D}$ concentrations was calculated over 13 years (older cohort) and over 6 years (younger cohort). Absolute change in CES-D score was also calculated over these time periods and checked for normality. Paired-samples $t$-tests were performed to assess whether changes over time in 25(OH)D and CES-D were statistically significant. Serum $25(\mathrm{OH}) \mathrm{D}$ change was used as continuous determinant, expressed per $10 \mathrm{nmol} / \mathrm{L}$. To compare participants with relatively large $25(\mathrm{OH}) \mathrm{D}$ decreases with those with large increases, it was also divided in tertiles with tertile 3 (increase in $25(\mathrm{OH}) \mathrm{D}$ concentration) serving as reference category. For the continuous baseline characteristics, linear regression analyses were used to examine linear trends across the tertiles of $25(\mathrm{OH}) \mathrm{D}$ change. For the categorical variables, chi-square (linear-by-linear association) tests were performed to test for trend. 
The associations between change in $25(\mathrm{OH}) \mathrm{D}$ and change in depressive symptoms over 13 or 6 years were analysed by multivariable linear regression analysis. Based on previous studies on $25(\mathrm{OH}) \mathrm{D}$ and depression $(11,14$, $15,24)$, sex was examined as a potential effect modifier. Another potential effect modifier was baseline serum 25(OH)D concentration, as this may influence the change in serum $25(\mathrm{OH}) \mathrm{D}(45)$. Effect modification was tested by including sex or baseline serum 25(OH)D (dichotomous, median-split) and the interaction term of the potential effect modifier with $25(\mathrm{OH}) \mathrm{D}$ change in the unadjusted regression models. A $P$ value $<0.10$ of the interaction term(s) was considered statistically significant. Three models were made: model 1 was adjusted for baseline serum $25(\mathrm{OH}) \mathrm{D}$ (to interpret the regression coefficient for subjects with the same $25(\mathrm{OH}) \mathrm{D}$ concentration at baseline); model 2 was additionally adjusted for age, sex and education level; and model 3 was additionally adjusted for the lifestyle factors BMI, physical activity, alcohol use and smoking. To test linear trends across the tertiles, the categorical tertile variable was used as a continuous variable to retrieve a $P$ value for trend.

Three sensitivity analyses were conducted. First, all analyses were additionally adjusted for number of chronic diseases in a separate model, as this covariate might confound and/or mediate the association causing potential overadjustment. Second, in order to check whether changes in lifestyle factors affect the association, model 3 was additionally adjusted for the changes in BMI, physical activity (both absolute continuous change), alcohol use and smoking (both categorical: stable, increase, decrease). Third, all analyses were repeated after exclusion of participants who used antidepressants at baseline or at one or more of the measurement cycles during the follow-up period.

All analyses were performed using SPSS version 23 (SPSS Inc.). A double-sided $P$ value of $<0.05$ was considered statistically significant.

\section{Results}

\section{Baseline characteristics}

Participants from the older cohort $(n=173)$ had a median age of 68.9 years (interquartile range (IQR): 67.0-72.3) and the mean baseline deseasonalised serum 25(OH)D was $58.2 \mathrm{nmol} / \mathrm{L}$ (standard deviation (s.D.): 16.1) (Table 1). The median age of participants from the younger cohort $(n=450)$ was 59.8 years (IQR: 57.0-62.2) and their mean baseline deseasonalised serum 25(OH)D was $59.5 \mathrm{nmol} / \mathrm{L}$
(s.D.: 17.9). When comparing the 25(OH)D change tertiles from the older cohort, participants from tertile 1 tended to be more educated and tended to drink more alcohol compared to the other tertiles. In the younger cohort, participants from tertile 1 were more often women and tended to have more chronic diseases.

Comparison of included $(n=173)$ and excluded ( $n=1336$, Fig. 1A) participants from the older cohort showed that excluded participants had lower 25(OH)D concentrations $(P<0.001)$, more depressive symptoms $(P<0.001)$, were older $(P<0.001)$, less physically active $(P<0.001)$, more often smokers $(P=0.002)$, drank less alcohol $(P<0.001)$ and had more chronic diseases $(P<0.001)$. In the younger cohort, this comparison showed that excluded participants $(n=469$, Fig. 1B) had more depressive symptoms $(P=0.044)$, were more often smokers $(P=0.004)$ and had more chronic diseases $(P=0.019)$ compared to included participants $(n=450)$.

\section{Absolute change in serum 25(OH)D concentrations and depressive symptoms}

Figure 2 shows the absolute, intra-individual change in serum $25(\mathrm{OH}) \mathrm{D}$ over 13 years for the older cohort and over 6 years for the younger cohort. The difference in distribution between the two cohorts becomes clear from the cutoff values of the tertiles. In the older cohort, 117 participants $(67.6 \%)$ experienced a decrease in $25(\mathrm{OH}) \mathrm{D}$ concentration, whereas this was $172(38.2 \%)$ in the younger cohort. Mean 25(OH)D of participants from the older cohort decreased by $6.9 \mathrm{nmol} / \mathrm{L}$ (s.D.: $20.9, P<0.001$ ). The mean CES-D score increased during the same time period by 2.0 points (s.D.: $6.5, P<0.001$ ), suggesting increasing depressive symptoms over time. In the younger cohort, mean $25(\mathrm{OH}) \mathrm{D}$ increased by $5.5 \mathrm{nmol} / \mathrm{L}$ (s.D.: 17.8, $P<0.001)$, and the mean CES-D score decreased by 0.7 points (s.D.: 6.5$)$ over 6 years $(P<0.027)$. Change in depressive symptoms was normally distributed in both cohorts.

\section{Association between change in serum 25(OH)D and change in depressive symptoms}

In the older cohort, change in serum $25(\mathrm{OH}) \mathrm{D}$ (as continuous determinant) was not associated with change in CES-D score after adjustment for baseline 25(OH)D concentration. Similarly, tertiles of $25(\mathrm{OH}) \mathrm{D}$ change did not show an association, and the $P$ for trend was not statistically significant $(0.246)$. No interactions with sex and baseline $25(\mathrm{OH}) \mathrm{D}$ were observed. 


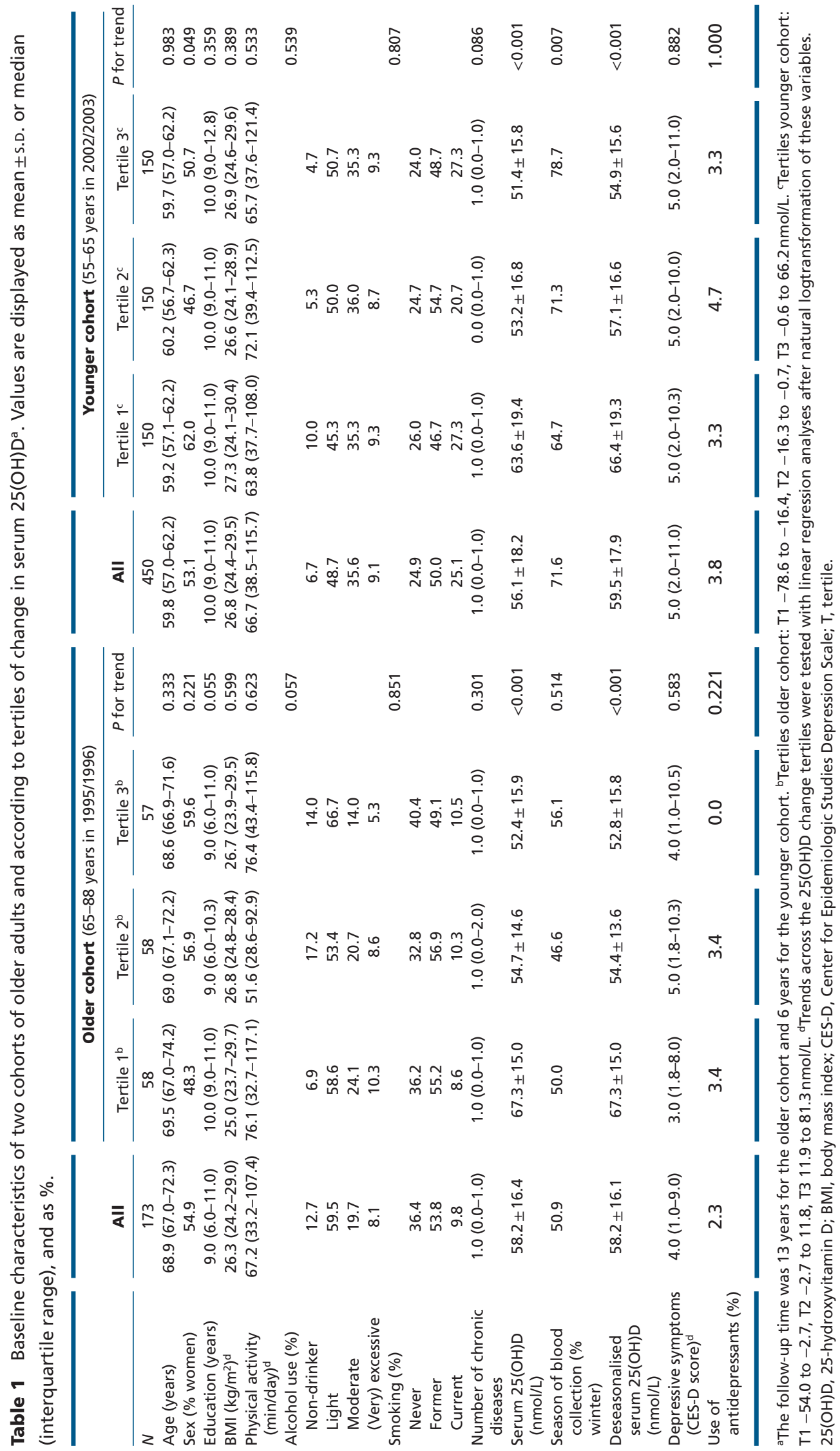



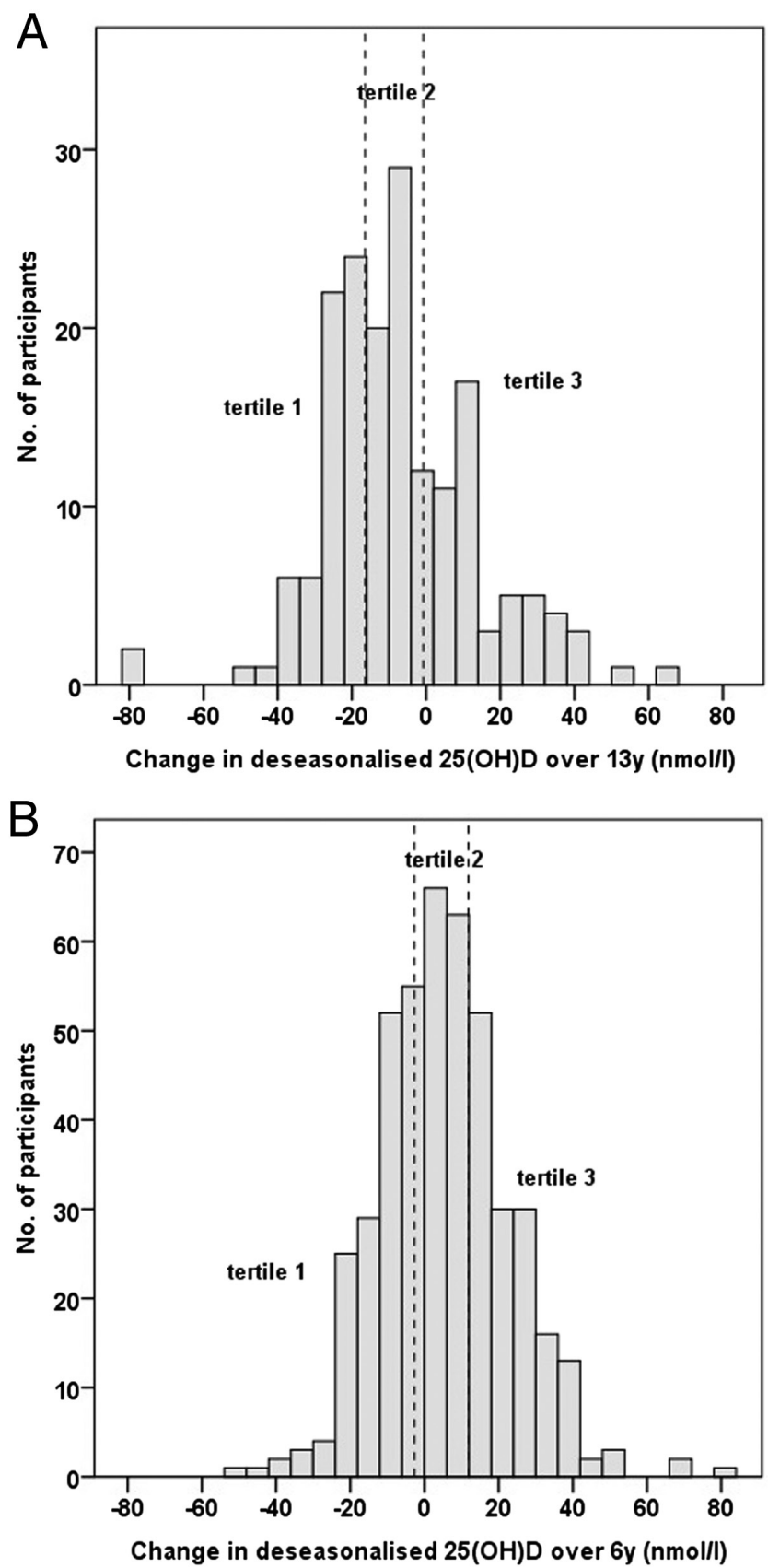

Figure 2

Histograms of change in deseasonalised serum 25-hydroxyvitamin D over 13 years in the older cohort $(A)$ and over 6 years in the younger cohort (B). Dashed lines indicate the cutoff values of the tertiles. The mean \pm S.D. changes in 25-hydroxyvitamin D were for tertile 1: $-27.1 \pm 12.0$, tertile 2: $-9.3 \pm 4.2$ and tertile $3: 16.2 \pm 14.3$.

In the younger cohort, significant interactions between change in $25(\mathrm{OH}) \mathrm{D}$ and both baseline $25(\mathrm{OH}) \mathrm{D}$ $(P=0.042)$ and sex $(P=0.087)$ were observed. After stratification for baseline $25(\mathrm{OH}) \mathrm{D}$, sex was no longer an effect modifier $(P=0.139$ and 0.453$)$. Participants below the median of $58.6 \mathrm{nmol} / \mathrm{L}$ showed a negative association (B per 10 nmol/L increase, model 3: -0.62 (95\% CI: -1.17 , $-0.07)$ ), meaning that a more positive $25(\mathrm{OH}) \mathrm{D}$ change (indicating less decrease or even an increase in 25(OH)D) was associated with a decrease in CES-D score (indicating a reduction in depressive symptoms). A similar association was observed for the 25(OH)D change tertiles (B tertile 1 vs tertile 3, model 3: 3.07 (95\% CI: 0.73, 5.40)). In participants with baseline $25(\mathrm{OH}) \mathrm{D}$ above the median, no associations were found (Table 2).

\section{Sensitivity analyses}

Additional adjustment for number of chronic diseases did not markedly change the findings in both cohorts. Similarly, additional adjustment for changes in four lifestyle factors did not change the findings. Furthermore, findings from the older cohort were similar when participants who used antidepressants at baseline $(n=4)$ or during follow-up ( $n=17)$ were excluded. In the younger cohort, exclusion of baseline antidepressant users $(n=17)$ or follow-up users $(n=26)$ resulted in somewhat stronger associations in those with a baseline $25(\mathrm{OH}) \mathrm{D}$ concentration below $58.6 \mathrm{nmol} / \mathrm{L}$ (e.g. in $n=424$ : B, tertile 1 vs tertile 3, model 3: 3.30 (95\% CI: 0.96, 5.63)).

\section{Discussion}

In this study, we observed no associations between change in serum $25(\mathrm{OH}) \mathrm{D}$ concentration and parallel change in depressive symptoms in a cohort of older adults (65-88 years at baseline, follow-up 13 years). Neither did we find associations in a younger cohort (55-65 years at baseline, follow-up 6 years) with a baseline 25(OH)D concentration above $59 \mathrm{nmol} / \mathrm{L}$. However, in participants from the younger cohort with a lower baseline $25(\mathrm{OH}) \mathrm{D}$, we observed that an increase in $25(\mathrm{OH}) \mathrm{D}$ concentration was associated with a decrease in severity of depressive symptoms.

The observed associations between change in $25(\mathrm{OH}) \mathrm{D}$ concentration and change in depressive symptoms differed between the two cohorts. In the younger cohort, a $10 \mathrm{nmol} / \mathrm{L}$ increase in serum $25(\mathrm{OH}) \mathrm{D}$ was associated with a 0.62 points lower CES-D score, but only if baseline 25(OH)D concentrations were relatively low. The null findings in the younger cohort's group with relatively 
Table 2 Associations between change in deseasonalised serum 25(OH)D and change in CES-D score.

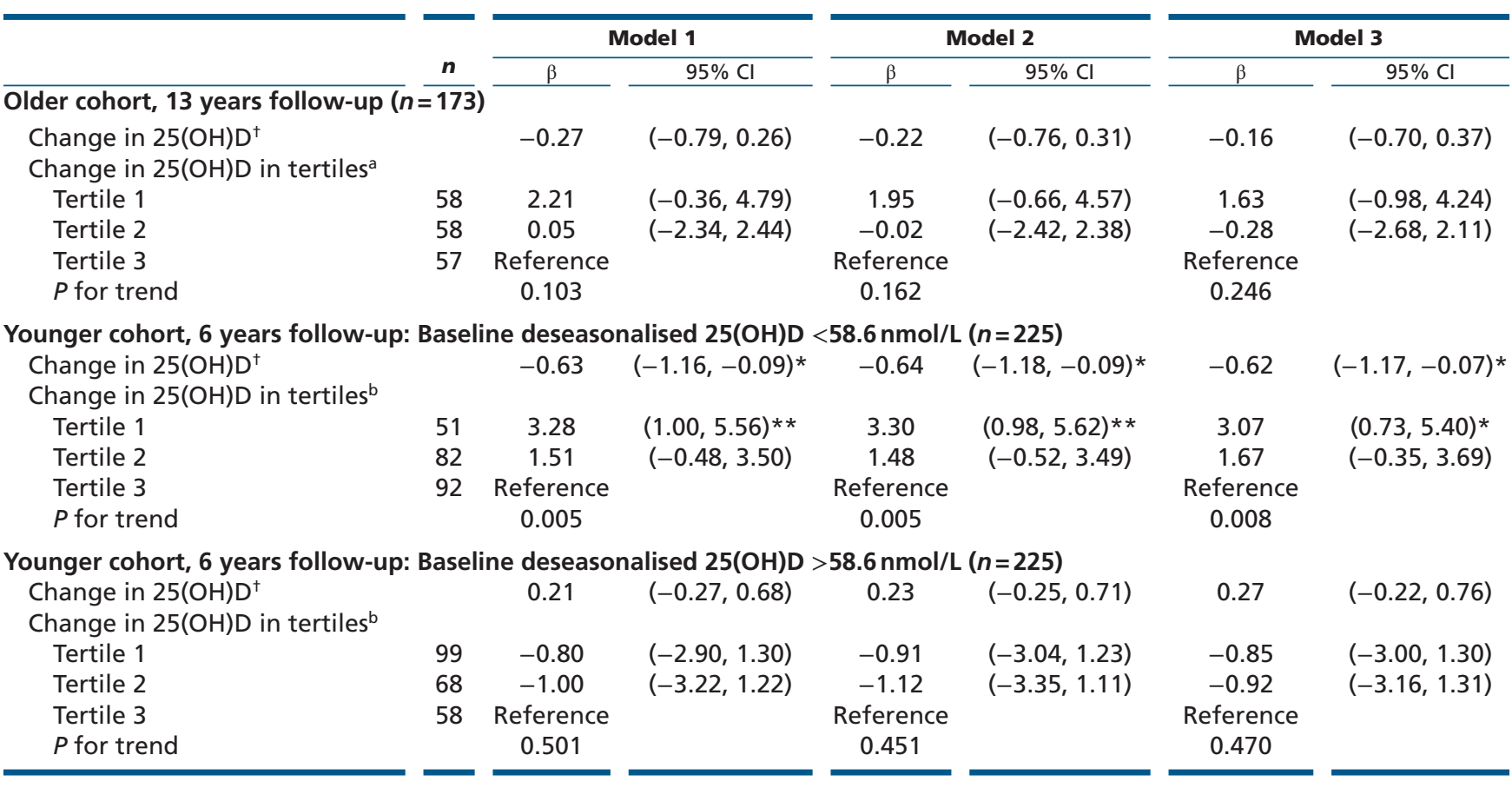

Model 1: adjusted for baseline standardised and deseasonalised 25(OH)D concentration. Model 2: additionally adjusted for age, sex and education level. Model 3: additionally adjusted for BMI, physical activity, alcohol use and smoking.

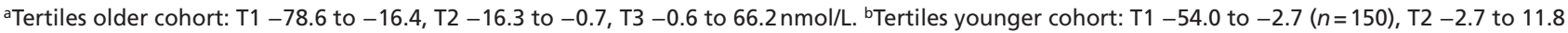
$(n=150)$, T3 11.9 to $81.3(n=150) \mathrm{nmol} / \mathrm{L}$.

$* P$-value $<0.05, * * P$-value $<0.01 ;{ }^{\dagger}$ Change in $25(\mathrm{OH}) \mathrm{D}$ (continuous, per $10 \mathrm{nmol} / \mathrm{L}$ ).

CES-D, Center for Epidemiologic Studies Depression scale; Cl, confidence interval; $\beta$, unstandardised regression coefficient.

high baseline 25(OH)D concentrations suggest that a change in $25(\mathrm{OH}) \mathrm{D}$ concentration above a certain level we used the median of $59 \mathrm{nmol} / \mathrm{L}$ - has less influence on depressive symptoms. However, this was not confirmed in the older cohort. An explanation for the non-significant association in the older cohort may be the small sample size $(n=173)$, which limited the statistical power. The betas of the older cohort were in the same direction and of comparable size as those in the younger cohort's group with relatively low baseline $25(\mathrm{OH}) \mathrm{D}$ concentrations.

To the best of our knowledge, this is the first observational study that investigated intra-individual change in $25(\mathrm{OH}) \mathrm{D}$ in relation to intra-individual change in depressive symptoms. Our results suggest that supplementation of vitamin $\mathrm{D}$ in those with relatively low baseline levels might positively influence depressive symptoms. Indeed, a 12-month vitamin D supplementation trial in overweight adults showed that 25(OH)D concentrations increased from 55 to $112 \mathrm{nmol} / \mathrm{L}$ in the group receiving $40000 \mathrm{IU}$ vitamin $\mathrm{D}_{3}$ per week and from 52 to $88 \mathrm{nmol} / \mathrm{L}$ in the group receiving $20000 \mathrm{IU}$ per week, compared to no change (from 52 to $50 \mathrm{nmol} / \mathrm{L}$ ) in the placebo group; the treatment groups had a significant greater reduction in depressive symptoms than the placebo group (25). However, other RCTs, which reported pre- and post-intervention $25(\mathrm{OH}) \mathrm{D}$ concentrations, showed a larger $25(\mathrm{OH}) \mathrm{D}$ increase in the treatment group but no effect on depression $(26,46)$ or mental well-being $(47,48)$. Thus, more research is needed to further elucidate the potential impact of $25(\mathrm{OH}) \mathrm{D}$ change on depressive symptoms.

In our previous prospective study, an inverse association between baseline $25(\mathrm{OH}) \mathrm{D}$ and depressive symptoms over 6 years was found only in women from the older LASA cohort (24). In the present study, with change in $25(\mathrm{OH}) \mathrm{D}$ as determinant instead of baseline $25(\mathrm{OH}) \mathrm{D}$, sex was not an effect modifier in the older cohort. Explanations for this might be differences in the study sample and the limited power ( $n=173$ vs 1282 ). In addition, De Koning, et al. (24) found no association in the younger cohort, whereas we did for those with low baseline 25(OH)D. This discrepancy might be explained by general health status: being healthy might be important to withstand negative effects on mood of a low $25(\mathrm{OH}) \mathrm{D}$, but not negative effects of a decrease in $25(\mathrm{OH}) \mathrm{D}$. 
In the present study, we also observed a difference between the two cohorts with respect to the distributions of $25(\mathrm{OH}) \mathrm{D}$ changes: $62 \%$ of the younger cohort had an increase in serum 25(OH)D concentration over 6 years, compared to $32 \%$ of the older cohort over 13 years. This difference might be explained by age differences (5565 years in the younger cohort at baseline vs $65-88$ years in the older cohort). Older persons may have reduced their outdoor activities with ageing due to for example functional limitations, leading to less exposure to sunlight $(9,49)$. Our results are similar to those of the Tromsø Study, in which subjects older than 65 years at baseline had a decrease in serum $25(\mathrm{OH}) \mathrm{D}$ of $0.3 \mathrm{nmol} / \mathrm{L}$ over 14 years, while those younger than 65 years had an increase of $2.0 \mathrm{nmol} / \mathrm{L}(P<0.05)(50)$. Furthermore, our mean 13-year change in $25(\mathrm{OH}) \mathrm{D}$ in the older cohort $(-6.9 \mathrm{nmol} / \mathrm{L})$ and 6 -year change in the younger cohort $(+5.5 \mathrm{nmol} / \mathrm{L})$ were comparable but slightly different to previous findings within LASA that were based on different statistical models and on measurements that were not yet standardised. Van Schoor et al. (40) showed that 25(OH)D concentrations decreased with $6.5 \mathrm{nmol} / \mathrm{L}$ in the older cohort and increased with $2.4 \mathrm{nmol} / \mathrm{L}$ in the younger cohort (see their Table 3: age per year (longitudinal)).

Our study has several strengths, including its longitudinal design, a nationally representative sample of older adults, and the use of deseasonalised serum 25(OH)D values at two time points. Further, the measurements of $25(\mathrm{OH}) \mathrm{D}$ were standardised for assay. Limitations of this study are the relatively healthy study population - as most participants needed to visit the hospital for blood sampling - and the exclusion of participants with only one serum 25(OH)D measurement that resulted in smaller and less representative samples. Moreover, our study was limited by the use of self-reported depressive symptoms during the past week instead of a clinical assessment; however, the CES-D scale has been shown to have good psychometric properties in samples of older adults (37). Reverse causality is a limitation as well, since we do not know when the changes occurred during the 13 or 6 years; an increase in depressive symptoms might have occurred before the decrease in $25(\mathrm{OH}) \mathrm{D}$. However, our previous paper showed that baseline $25(\mathrm{OH}) \mathrm{D}$ was associated with the onset of depressive symptoms over 6 years in older women without depressive symptoms at baseline (24). This indicated an association in the direction from 25(OH)D to depression, which was the assumption for the present study. Lastly, no data on supplement use or nutritional intake of vitamin D were available. However, measured 25(OH)D concentrations are a more valid estimate of vitamin D status than intake from foods and supplements (33).

In conclusion, our study suggests that a decrease in serum $25(\mathrm{OH}) \mathrm{D}$ concentration over 6 years is associated with a parallel increase in depressive symptoms in young older adults with a low baseline 25(OH)D. We did not observe an association in young older adults with a higher baseline 25(OH)D over 6 years, or in older adults over a period of 13 years. Whether specific groups may emotionally benefit from an increase in vitamin D concentration (e.g. persons with relative low 25(OH)D concentrations) needs further investigation; welldesigned RCTs are needed to determine the potential causal association between vitamin D and depression.

\section{Declaration of interest}

The authors declare that there is no conflict of interest that could be perceived as prejudicing the impartiality of this study.

\section{Funding}

The Longitudinal Aging Study Amsterdam is supported by a grant from the Netherlands Ministry of Health Welfare and Sports, Directorate of Long-Term Care. Funding for this paper was provided by the European Union FP7 MooDFOOD Project 'Multi-country cOllaborative project on the rOle of Diet, FOod-related behaviour, and Obesity in the prevention of Depression' (grant agreement no. 613598). Standardisation of serum 25(OH)D values was supported by funding received from the European Commission under its Seventh Framework Programme (ODIN; grant agreement no. 613977).

\section{Acknowledgements}

The authors are grateful to all LASA participants for their valued contributions. In addition, they would like to thank Prof. Jos Twisk for his advice regarding the statistical analyses.

\section{References}

1 Ferrari AJ, Charlson FJ, Norman RE, Patten SB, Freedman G, Murray CJL, Vos T \& Whiteford HA. Burden of depressive disorders by country, sex, age, and year: findings from the Global Burden of Disease Study 2010. PLOS Medicine 201310 e1001547. (https://doi. org/10.1371/journal.pmed.1001547)

2 Alexopoulos GS. Depression in the elderly. Lancet 2005365 1961-1970. (https://doi.org/10.1016/S0140-6736(05)66665-2)

3 Blazer DG. Depression in late life: review and commentary. Journals of Gerontology, Series A: Biological Sciences and Medical Sciences $2003 \mathbf{5 8}$ 249-265. (https://doi.org/10.1093/gerona/58.3.M249)

4 Penninx B, Milaneschi Y, Lamers F \& Vogelzangs N. Understanding the somatic consequences of depression: biological mechanisms and the role of depression symptom profile. BMC Medicine 201311129. (https://doi.org/10.1186/1741-7015-11-129)

5 Eyles DW, Smith S, Kinobe R, Hewison M \& McGrath JJ. Distribution of the vitamin D receptor and 1 alpha-hydroxylase in human brain. Journal of Chemical Neuroanatomy 200529 21-30. (https://doi. org/10.1016/j.jchemneu.2004.08.006) 
6 Kesby JP, Eyles DW, Burne THJ \& McGrath JJ. The effects of vitamin $\mathrm{D}$ on brain development and adult brain function. Molecular and Cellular Endocrinology 2011347 121-127. (https://doi.org/10.1016/j. mce.2011.05.014)

7 Annweiler C, Schott AM, Berrut G, Chauviré V, Le Gall D, Inzitari $\mathrm{M} \&$ Beauchet $\mathrm{O}$. Vitamin $\mathrm{D}$ and ageing: neurological issues. Neuropsychobiology 201062 139-150. (https://doi. org/10.1159/000318570)

8 Humble MB. Vitamin D, light and mental health. Journal of Photochemistry and Photobiology B: Biology 2010101 142-149. (https://doi.org/10.1016/j.jphotobiol.2010.08.003)

9 Lips P, van Schoor NM \& de Jongh RT. Diet, sun, and lifestyle as determinants of vitamin D status. Annals of the New York Academy of Sciences 20141317 92-98. (https://doi.org/10.1111/nyas.12443)

10 Hoogendijk WJG, Lips P, Dik MG, Deeg DH, Beekman AF $\&$ Penninx BH. Depression is associated with decreased 25-hydroxyvitamin $\mathrm{d}$ and increased parathyroid hormone levels in older adults. Archives of General Psychiatry 200865 508-512. (https:// doi.org/10.1001/archpsyc.65.5.508)

11 Imai CM, Halldorsson TI, Eiriksdottir G, Cotch MF, Steingrimsdottir L, Thorsdottir I, Launer LJ, Harris T, Gudnason V \& Gunnarsdottir I. Depression and serum 25-hydroxyvitamin D in older adults living at northern latitudes - AGES-Reykjavik study. Journal of Nutritional Science 20154 e37. (https://doi.org/10.1017/ jns.2015.27)

12 Pan A, Lu L, Franco OH, Yu Z, Li H \& Lin X. Association between depressive symptoms and 25-hydroxyvitamin $\mathrm{D}$ in middle-aged and elderly Chinese. Journal of Affective Disorders 2009118 240-243. (https://doi.org/10.1016/j.jad.2009.02.002)

13 Zhao G, Ford ES, Li C \& Balluz LS. No associations between serum concentrations of 25-hydroxyvitamin D and parathyroid hormone and depression among US adults. British Journal of Nutrition $2010 \mathbf{1 0 4}$ 1696-1702. (https://doi.org/10.1017/S0007114510002588)

14 May HT, Bair TL \& Lappe DL. Association of vitamin D levels with incident depression among a general cardiovascular population. American Heart Journal 2010159 1037-1043. (https://doi. org/10.1016/j.ahj.2010.03.017)

15 Milaneschi Y, Shardell M, Corsi AM, Vazzana R, Bandinelli S \& Guralnik JM. Serum 25-hydroxyvitamin D and depressive symptoms in older women and men. Journal of Clinical Endocrinology and Metabolism 201095 3225-3233. (https://doi.org/10.1210/jc.20100347)

16 Williams JA, Sink KM, Tooze JA, Atkinson HH, Cauley JA, Yaffe K, Tylavsky FA, Rubin SM, Simonsick EM \& Kritchevsky SB et al. Low 25-hydroxyvitamin D concentrations predict incident depression in well-functioning older adults: the Health, Aging, and Body Composition Study. Journals of Gerontology, Series A: Biological Sciences and Medical Sciences 201570 757-763. (https://doi.org/10.1093/ gerona/glu184)

17 Maddock J, Berry DJ, Geoffroy MC, Power C \& Hyppönen E. Vitamin $\mathrm{D}$ and common mental disorders in mid-life: cross-sectional and prospective findings. Clinical Nutrition 201332 758-764. (https://doi. org/10.1016/j.clnu.2013.01.006)

18 Brouwer-Brolsma EM, Dhonukshe-Rutten RAM, van Wijngaarden JP, van der Zwaluw NL, Sohl E, In't Veld PH, van Dijk SC, Swart KMA, Enneman AW \& Ham AC et al. Low vitamin D status is associated with more depressive symptoms in Dutch older adults. European Journal of Nutrition 201655 1525-1534. (https://doi.org/10.1007/ s00394-015-0970-6)

19 Jovanova O, Aarts N, Noordam R, Carola-Zillikens M, Hofman A $\&$ Tiemeier H. Vitamin D serum levels are cross-sectionally but not prospectively associated with late-life depression. Acta Psychiatrica Scandinavica 2017135 185-194. (https://doi.org/10.1111/ acps.12689)

20 Toffanello ED, Sergi G, Veronese N, Perissinotto E, Zambon S, Coin A, Sartori L, Musacchio E, Corti M-C \& Baggio G et al. Serum 25-hydroxyvitamin D and the onset of late-life depressive mood in older men and women: the Pro.V.A. Study. Journals of Gerontology, Series A: Biological Sciences and Medical Sciences 201469 1554-1561. (https://doi.org/10.1093/gerona/glu081)

21 Chan R, Chan D, Woo J, Ohlsson C, Mellström D, Kwok T \& Leung P. Association between serum 25-hydroxyvitamin D and psychological health in older Chinese men in a cohort study. Journal of Affective Disorders 2011130 251-259. (https://doi.org/10.1016/j. jad.2010.10.029)

22 Almeida OP, Hankey GJ, Yeap BB, Golledge J \& Flicker L. Vitamin D concentration and its association with past, current and future depression in older men: the Health In Men Study. Maturitas 201581 36-41. (https://doi.org/10.1016/j.maturitas.2015.01.016)

23 Husemoen LLN, Ebstrup JF, Mortensen EL, Schwarz P, Skaaby T, Thuesen BH, Jorgensen T \& Linneberg A. Serum 25-hydroxyvitamin $\mathrm{D}$ and self-reported mental health status in adult Danes. European Journal of Clinical Nutrition $2016 \mathbf{7 0}$ 78-84. (https://doi.org/10.1038/ ejcn.2015.129)

24 De Koning EJ, Elstgeest LEM, Comijs HC, Lips P, Rijnhart JJM, Van Marwijk HWJ, Beekman ATF, Visser M, Penninx BWJH \& Van Schoor NM. Vitamin D status and depressive symptoms in older adults: a role for physical functioning? American Journal of Geriatric Psychiatry 2018 Epub. (https://doi.org/10.1016/j.jagp.2018.03.004 )

25 Jorde R, Sneve M, Figenschau Y, Svartberg J \& Waterloo K. Effects of vitamin D supplementation on symptoms of depression in overweight and obese subjects: randomized double blind trial. Journal of Internal Medicine 2008264 599-609. (https://doi.org/10.1111/ j.1365-2796.2008.02008.x)

26 Kjaergaard M, Waterloo K, Wang CE, Almas B, Figenschau Y, Hutchinson MS, Svartberg J \& Jorde R. Effect of vitamin D supplement on depression scores in people with low levels of serum 25-hydroxyvitamin D: nested case-control study and randomised clinical trial. British Journal of Psychiatry 2012201 360-368. (https:// doi.org/10.1192/bjp.bp.111.104349)

27 Shaffer JA, Edmondson D, Wasson LT, Falzon L, Homma K, Ezeokoli N, Li P \& Davidson KW. Vitamin D supplementation for depressive symptoms: a systematic review and meta-analysis of randomized controlled trials. Psychosomatic Medicine 201476 190-196. (https://doi.org/10.1097/PSY.0000000000000044)

28 Li G, Mbuagbaw L, Samaan Z, Falavigna M, Zhang S, Adachi JD, Cheng J, Papaioannou A \& Thabane L. Efficacy of vitamin D supplementation in depression in adults: a systematic review. Journal of Clinical Endocrinology and Metabolism 201499 757-767. (https:// doi.org/10.1210/jc.2013-3450)

29 Spedding S. Vitamin D and depression: a systematic review and meta-analysis comparing studies with and without biological flaws. Nutrients 20146 1501. (https://doi.org/10.3390/nu6041501)

30 Rejnmark L, Bislev LS, Cashman KD, Eiríksdottir G, Gaksch M, Grübler M, Grimnes G, Gudnason V, Lips P \& Pilz S et al. Nonskeletal health effects of vitamin $\mathrm{D}$ supplementation: a systematic review on findings from meta-analyses summarizing trial data. PLoS ONE 201712 e0180512. (https://doi.org/10.1371/journal. pone.0180512)

31 Okereke OI \& Singh A. The role of vitamin D in the prevention of late-life depression. Journal of Affective Disorders 2016198 1-14. (https://doi.org/10.1016/j.jad.2016.03.022)

32 Maxwell JD. Seasonal variation in vitamin D. Proceedings of the Nutrition Society 199453 533-543. (https://doi.org/10.1079/ PNS19940063)

33 Millen AE \& Bodnar LM. Vitamin D assessment in population-based studies: a review of the issues. American Journal of Clinical Nutrition 200887 1102S-1105S. (https://doi.org/10.1093/ajcn/87.4.1102S)

34 Huisman M, Poppelaars J, van der Horst M, Beekman AT, Brug J, van Tilburg TG \& Deeg DJ. Cohort profile: the Longitudinal Aging Study Amsterdam. International Journal of Epidemiology 201140 868-876. (https://doi.org/10.1093/ije/dyq219) 
35 Hoogendijk EO, Deeg DJH, Poppelaars J, van der Horst M, Broese van Groenou MI, Comijs HC, Pasman HRW, van Schoor NM, Suanet B \& Thomése F et al. The Longitudinal Aging Study Amsterdam: cohort update 2016 and major findings. European Journal of Epidemiology 201631 927-945. (https://doi.org/10.1007/s10654-016-0192-0)

36 Radloff LS. The CES-D scale: a self-report depression scale for research in the general population. Applied Psychological Measurement 19771 385-401. (https://doi.org/10.1177/014662167700100306)

37 Beekman ATF, Deeg DJH, Van Limbeek J, Braam AW, De Vries MZ \& Van Tilburg W. Criterion validity of the Center for Epidemiologic Studies Depression scale (CES-D): results from a community-based sample of older subjects in the Netherlands. Psychological Medicine 199727 231-235. (https://doi.org/10.1017/S0033291796003510)

38 Cashman KD, Dowling KG, Škrabáková Z, Gonzalez-Gross M, Valtueña J, De Henauw S, Moreno L, Damsgaard CT, Michaelsen KF, Mølgaard C et al. Vitamin D deficiency in Europe: pandemic? American Journal of Clinical Nutrition 2016103 1033-1044. (https:// doi.org/10.3945/ajcn.115.120873)

39 Sempos CT, Vesper HW, Phinney KW, Thienpont LM \& Coates PM. Vitamin D status as an international issue: national surveys and the problem of standardization. Scandinavian Journal of Clinical and Laboratory Investigation 2012243 32-40. (https://doi.org/10.3109/003 65513.2012.681935)

40 Van Schoor NM, Knol DL, Deeg DJ, Peters FP, Heijboer AC \& Lips P. Longitudinal changes and seasonal variations in serum 25-hydroxyvitamin D levels in different age groups: results of the Longitudinal Aging Study Amsterdam. Osteoporosis International 2014 25 1483-1491. (https://doi.org/10.1007/s00198-014-2651-3)

41 Van der Mei IAF, Ponsonby A-L, Dwyer T, Blizzard L, Taylor BV, Kilpatrick T, Butzkueven H \& McMichael AJ. Vitamin D levels in people with multiple sclerosis and community controls in Tasmania, Australia. Journal of Neurology 2007254 581-590. (https://doi. org/10.1007/s00415-006-0315-8)

42 Sachs MC, Shoben A, Levin GP, Robinson-Cohen C, Hoofnagle AN, Swords-Jenny N, Ix JH, Budoff M, Lutsey PL \& Siscovick DS et al. Estimating mean annual 25-hydroxyvitamin D concentrations from single measurements: the Multi-Ethnic Study of Atherosclerosis.
American Journal of Clinical Nutrition 201397 1243-1251. (https:// doi.org/10.3945/ajcn.112.054502)

43 Garretsen HFL. Probleemdrinken: prevalentiebepaling, beïnvloedende factoren en preventiemogelijkheden, Theoretische overwegingen en onderzoek in Rotterdam. Lisse, The Netherlands: Swets \& Zeitlinger, 1983.

44 Stel VS, Smit JH, Pluijm SM, Visser M, Deeg DJ \& Lips P. Comparison of the LASA Physical Activity Questionnaire with a 7-day diary and pedometer. Journal of Clinical Epidemiology 200457 252-258. (https:// doi.org/10.1016/j.jclinepi.2003.07.008)

45 Aloia JF, Patel M, DiMaano R, Li-Ng M, Talwar SA, Mikhail M, Pollack S \& Yeh JK. Vitamin D intake to attain a desired serum 25-hydroxyvitamin D concentration. American Journal of Clinical Nutrition 200887 1952-1958. (https://doi.org/10.1093/ ajcn/87.6.1952)

46 Arvold D, Odean M, Dornfeld M, Regal R, Arvold J, Karwoski G, Mast D, Sanford P \& Sjoberg R. Correlation of symptoms with vitamin $\mathrm{D}$ deficiency and symptom response to cholecalciferol treatment: a randomized controlled trial. Endocrine Practice 200915 203-212. (https://doi.org/10.4158/EP.15.3.203)

47 Sanders KM, Stuart AL, Williamson EJ, Jacka FN, Dodd S, Nicholson G \& Berk M. Annual high-dose vitamin D3 and mental well-being: randomised controlled trial. British Journal of Psychiatry 2011198 357-364. (https://doi.org/10.1192/bjp.bp.110.087544)

48 Grant AM. Oral vitamin D3 and calcium for secondary prevention of low-trauma fractures in elderly people (Randomised Evaluation of Calcium Or vitamin D, RECORD): a randomised placebo-controlled trial. Lancet 2005365 1621-1628. (https://doi.org/10.1016/S01406736(05)63013-9)

49 Holick MF. Environmental factors that influence the cutaneous production of vitamin D. American Journal of Clinical Nutrition 1995 61 638S-645S. (https://doi.org/10.1093/ajen/61.3.638S)

50 Jorde R, Sneve M, Hutchinson M, Emaus N, Figenschau Y \& Grimnes G. Tracking of serum 25-hydroxyvitamin D levels during 14 years in a population-based study and during 12 months in an intervention study. American Journal of Epidemiology 2010171 903-908. (https://doi.org/10.1093/aje/kwq005)

Received 5 March 2018

Revised version received 12 July 2018

Accepted 27 July 2018 